\title{
BMJ Open Marital status and risk of dementia: a nationwide population-based prospective study from Sweden
}

\author{
Anna Sundström, ${ }^{1,2}$ Olle Westerlund, ${ }^{2,3}$ Elena Kotyrlo ${ }^{2}$
}

To cite: Sundström A, Westerlund 0, Kotyrlo E. Marital status and risk of dementia: a nationwide population-based prospective study from Sweden. BMJ Open 2016;6:e008565. doi:10.1136/bmjopen-2015008565

- Prepublication history for this paper is available online. To view these files please visit the journal online (http://dx.doi.org/10.1136/ bmjopen-2015-008565).

Received 21 April 2015 Revised 7 September 2015 Accepted 21 October 2015

CrossMark

For numbered affiliations see end of article.

Correspondence to Dr Anna Sundström; anna.sundstrom@umu.se

\section{ABSTRACT}

Objectives: To examine the association between marital status and dementia in a cohort of young-old (50-64) and middle-old (65-74) adults, and also whether this may differ by gender.

Design: Prospective population-based study with follow-up time of up to 10 years.

Setting: Swedish national register-based study. Participants: 2288489 individuals, aged 5074 years, without prior dementia diagnosis at baseline. Dementia was identified using the Swedish National Patient Register and the Cause of Death Register.

Outcome measures: The influence of marital status on dementia was analysed using Cox proportional hazards models, adjusted stepwise for multiple covariates (model 1: adjusted for age and gender; and model 2: additionally adjusted for having adult children, education, income and prior cardiovascular disease).

Results: During follow-up, 31572 individuals in the study were identified as demented. Cox regression showed each non-married subcategory to be associated with a significantly higher risk of dementia than the married group, with the highest risk observed among people in the young-old age group, especially among those who were divorced or single (HRs 1.79 vs 1.71 , fully adjusted model). Analyses stratified by gender showed gender differences in the young-old group, with indications of divorced men having a higher relative risk compared with divorced women (HRs 2.1 vs 1.7, only-age adjusted model). However, in the fully adjusted model, these differences were attenuated and there was no longer any significant difference between male and female participants.

Conclusions: Our results suggest that those living alone as non-marrieds may be at risk for early-onset and late-onset dementia. Although more research is needed to understand the underlying mechanism by which marital status is associated with dementia, this suggests that social relationships should be taken seriously as a risk factor for dementia and that socialbased interventions may provide an opportunity to reduce the overall dementia risk.

\section{INTRODUCTION}

Owing to the global increase in life expectancy, the number of people suffering from

\section{Strengths and limitations of this study}

- The study was based on data from various Swedish registers and includes the entire Swedish population, aged $50-74$ years at baseline, with a follow-up period of up to 10 years.

- Owing to the large sample size, we were able to estimate risk for subcategories of unmarried status and to divide the sample into gender and age groups (50-64 and 65-74 years).

- Limitations concern the use of dementia identification from national registers, which may underreport cases of dementia.

- Time in respective marital statuses was unavailable, which may have affected the results.

age-related diseases such as dementia will rise substantially and represents one of the most serious challenges of the 21st century. ${ }^{1}$ Therefore, it is increasingly important to identify attributes and groups at increased risk and factors that can reduce the risk of dementia.

A growing body of the literature indicates that aspects of social relationships are associated with the incidence of dementia. ${ }^{2}{ }^{3}$ One aspect that has drawn increasing interest in recent years concerns the effect of marriage on dementia. Among the few studies explicitly investigating this, the majority have found marriage/cohabitation to have a beneficial effect on dementia risk, ${ }^{3-7}$ although this is not consistently reported. ${ }^{8}$ Moreover, there is conflicting evidence as to whether all or just some unmarried states are related to dementia risk; whereas some studies have found an association only for those who are single, ${ }^{35}$ others have reported an association for single and divorced people ${ }^{4}$ while still others have found increased risk of dementia only among widows/widowers. ${ }^{6} 7$

Many researchers have highlighted gender differences in the effect of marital status on various physical health outcomes, generally showing men to benefit more from marriage than women do. ${ }^{9}{ }^{10}$ For example, one study reported a $250 \%$ higher mortality rate for 
unmarried compared with married men, and a $50 \%$ higher mortality rate for unmarried compared with married women. ${ }^{11}$ Furthermore, a longitudinal study of a Finnish cohort ${ }^{6}$ found non-cohabitant men to demonstrate higher ratios of experiencing a cognitive impairment later in life compared with non-cohabitant women. Although it is reasonable to believe that there may be gender differences in dementia risk among the single, divorced and widowed, to the best of our knowledge this has not been explicitly examined before.

The aim of this study was to evaluate the association between marital status and dementia while controlling for potential confounders. We also assessed whether there were differences in risk of dementia across the marital status categories. Moreover, in order to investigate whether there are differences between early and late onset of dementia, we separate the analysis into two age groups: young-old (50-64) and middle-old (65-74). Finally, since there may be gender differences in the association between marital status and dementia, we separated the analyses for men and women. Our study uses data from an extensive national registry that encompasses the entire Swedish population. These data also have the added benefit of having a long follow-up period (up to 10 years).

\section{METHOD}

Data

The study was based on data from the Linnaeus database comprising longitudinal nationwide data with linked records from various registers, including data from the National Patient Register and the Cause of Death Register. ${ }^{12}$ The National Patient Register covers all in-patient hospitalisations in Sweden and includes the entire Swedish population. The National Patient Register has been shown to demonstrate a high level of completeness, with a predictive value of about $85-95 \%$ for most diagnoses. ${ }^{13}$ The Cause of Death Register covers all deceased persons since 1952 who were residents of Sweden at the time of death, and includes official death certificates. The register offers low under-reporting; for example, in 2000, the nonreporting rate was less than $0.58 \%$ of all deaths. ${ }^{14}$ Both registers are based on diagnoses according to the International Classification of Diseases (ICD).

The Linnaeus database also includes yearly records of individual and family characteristics, for example, marital status, income, education and number of children, for all Swedish citizens from various registers held by Statistics Sweden.

\section{Study population and end point}

The study population was defined as the total Swedish population aged 50-74 years (born 1923-1947) registered as residents in Sweden as of 31 December 1997, amounting to 2326013 individuals. A total of 37 524 persons were excluded due to having been diagnosed with dementia prior to baseline (5459), emigration or death at entry (13), or having missing data on any of the baseline characteristics (32 052). Hence, the final study population comprised 2288489 individuals.

The study populations were followed up to 31 December 2006, through the linked registers in the Linnaeus database. Follow-up ended at the first of the following: date of dementia diagnosis, death or end of the study period.

\section{Marital status}

Information on marital status was obtained from Statistics Sweden. Marital status in 1997 was selected as the current marital status, and was classified into four categories: (1) married, (2) single, (3) divorced or (4) widowed.

\section{Ascertainment of dementia}

Dementia was identified using both the National Patient Register and the Cause of Death Register. In previous studies, combining the two registers has been found to enhance the detection rate; ${ }^{15}{ }^{16}$ hence, this approach was used in the present study. The registers have been reported to have high specificity for detecting dementia, but lower sensitivity (eg, missing dementia cases). Of note is that, despite the moderate sensitivities, data on dementia from these registers have been considered to be overall accurate, specific and feasible for conducting dementia cohort studies. ${ }^{15} 16$

To identify a dementia diagnosis, the following codes from the ICD, 10th Revision (ICD-10) were used: F00.0-9, F01.0-9, F02.0-8, F03, F03.9, G30.0-9, G31.9, and R54.9. Both diagnoses/death causes listed as primary or secondary (eg, the first 7 diagnoses/death causes in the register) were considered. In the analyses, all dementia groups were combined to define dementia (yes/no). If there were multiple reports of dementia diagnosis, we recorded only the date of the first admission.

\section{Covariates}

Analyses were adjusted for variables measuring attributes that have been shown in previous literature to be potential confounders: age, having adult children, education (classified as low $(\leq 9)$, intermediate $(10-12)$ and high ( $\geq 13$ years $)$. We further adjusted for taxable income and history of cardiovascular diseases during the years 1987-1996. Cardiovascular diseases were defined as the first hospitalisation caused by coronary heart disease, stroke or heart failure, and were coded according to the ICD-9 codes (410-414, 428, 430-438 and 440-448).

\section{Statistical analyses}

Multivariate adjusted Cox's proportional hazard regression models were used to analyse the association between marital status and incidence of dementia. In model 1, we adjusted for age and gender. In model 2, additional adjustments were made for having adult children, education, income and prior cardiovascular 
disease. Finally, to examine possible age and gender differences in the association between marital status and incidence of dementia, we repeated all analyses separately for the two age cohorts $(50-64,65-75$ years) and for the two genders. Time to event was calculated from the time of enrolment in the study until the time of dementia diagnosis, of being lost to follow-up, death or date of final follow-up, whichever event came first.

The results are presented as HRs with a 95\% CI. Statistical analyses were performed using SPSS Statistics V.22.

\section{RESULTS}

Background characteristics of the study population, by marital status and gender, are listed in table 1 . The mean age of the individuals at entry was $60.5( \pm 7.3)$ years, and the proportion of women was $51.0 \%$. Among men and women, those who were widowed were older and had lower levels of education as well as more often a history of prior cardiovascular diseases in comparison to the other marital status categories. Married men had the highest income and single women the highest education. Mean follow-up time was 6 years for individuals who were diagnosed as demented (defined either through diagnoses or death causes) and 8.6 years for those who remained dementia-free.

During the follow-up period, observations of dementia were found in 31572 individuals. The mean age of dementia onset differed depending on marital status: 74.9 years for married women, 74.8 years for married men, 73.3 years for single women, 72.2 years for single men, 73.5 years for divorced women, 72.0 years for divorced men, 76.6 years for widowed women and 76.0 years for widowed men.

To assess whether marital status influences the risk of dementia differently before and after the age of 65 years, the population was divided into two age groups: young-old (50-64 years) and middle-old (6574 years). The mean age at baseline of those in the young-old group $(\mathrm{n}=1538360)$ was $56.1 \quad( \pm 4.3)$ years, while the mean age in the middle-old group $(\mathrm{n}=750129)$ was $69.4( \pm 2.9)$ years. During follow-up, dementia diagnoses were recorded for 5850 individuals in the young-old group and for 25722 individuals in the middle-old group.

\section{Association between marital status and dementia}

We evaluated the impact of marital status on incidence of dementia for the two age groups using Cox proportional regression analysis and adjusted for multiple covariates. In the young-old group and for the basic model (model 1, adjusted for age and gender), each nonmarried subcategory was significantly associated with a higher risk of dementia relative to the married sample, with the highest risk observed for the divorced group (HR 2.05, 95\% CI 1.91 to 2.21) and the single group (1.91, 1.79 to 2.03). A slightly lower, but still significant, increased risk was observed among the widowed 1.38 (1.23 to 1.54). Also, in the middle-old group (model 1), each non-married subcategory showed a significantly higher risk of dementia compared with the married group. Similar to the young-old group, in the middle-old group the highest risk was observed for those who were divorced $(1.42,1.37$ to 1.47$)$, followed by singles (1.26, 1.21 to 1.32 ) and widowed (1.12, 1.08 to 1.16$)$.

After additional adjustment for having adult children, education, income and prior cardiovascular diseases (model 2), the HRs were attenuated but continued to be statistically significant for all non-married categories. As can be seen in table 2, the HRs were somewhat higher in the young-old, compared with the middle-old, group, and were particularly high for those divorced (HRs: young-old; 1.79 and middle-old; 1.42), followed by singles (young-old; 1.71 and middle-old; 1.23). Thus, although a significant association was noted for both age groups, this association was more pronounced for the young-old group. The estimated HRs for widows (young-old; 1.28 and middle-old; 1.12) were significantly lower in comparison with the other non-married groups in both age groups, but still showed a statistically significant increase in risk compared with married individuals. Note that the overall average risk is very low for the younger cohort (3.8 promille) and almost 10 times higher for the older cohort (3.4\%).

\section{Association between marital status and dementia by gender}

To examine possible gender differences in the association between marital status and dementia, we reran all models stratified by gender (table 3 ). There was a statistically significant gender difference between men and women in the young-old group, with divorced men showing a higher risk compared with divorced women (men; 2.10 and women; 1.70). However, this gender difference was considerably reduced after adjustment was made for the extended set of confounders in model 2 (men; 1.89 and women; 1.68). Thus, the gender differences shown in the estimates of model 1 seem to be partially driven by gender differences in socioeconomic status (eg, education and income) and other confounders.

Even though there were also higher risk ratios for men than women in the middle-old group (see table 3), these differences were not significantly different between the two genders and were further reduced in the fully adjusted model.

To summarise, the gender-specific estimates suggest an increased risk of dementia for unmarried men and women, particularly among the young-old, and a substantially smaller, though still statistically significant, risk for widowed men and women.

\section{DISCUSSION}

In this large, nationwide population-based study encompassing approximately two million individuals, it was 
Table 1 Baseline characteristics of the study sample by marital status

\begin{tabular}{|c|c|c|c|c|c|c|c|c|}
\hline \multirow[b]{2}{*}{ Characteristic } & \multicolumn{4}{|l|}{ Men } & \multicolumn{4}{|l|}{ Women } \\
\hline & $\begin{array}{l}\text { Married } \\
(n=762962)\end{array}$ & $\begin{array}{l}\text { Single } \\
(n=150 \text { 974) }\end{array}$ & $\begin{array}{l}\begin{array}{l}\text { Divorced } \\
(n=167763)\end{array} \\
\end{array}$ & $\begin{array}{l}\text { Widowed } \\
(n=38674)\end{array}$ & $\begin{array}{l}\text { Married } \\
(\mathrm{n}=721792)\end{array}$ & $\begin{array}{l}\text { Single } \\
(n=96115)\end{array}$ & $\begin{array}{l}\text { Divorced } \\
(n=197482)\end{array}$ & $\begin{array}{l}\text { Widowed } \\
(n=152727)\end{array}$ \\
\hline $\begin{array}{l}\text { Mean }(S D) \\
\text { age, years }\end{array}$ & $60.5(7.3)$ & $58.7(7.2)$ & $59.1(6.7)$ & $66.0(6.7)$ & $60.2(7.2)$ & $59.0(7.4)$ & $59.3(6.9)$ & $66.5(6.4)$ \\
\hline \multicolumn{9}{|c|}{ Education level, years } \\
\hline$\leq 9$ & $41.3 \%$ & $56.5 \%$ & $42.7 \%$ & $53.8 \%$ & $43.7 \%$ & $39.3 \%$ & $37.7 \%$ & $59.5 \%$ \\
\hline $10-12$ & $39.7 \%$ & $32.6 \%$ & $41.9 \%$ & $34.2 \%$ & $38.0 \%$ & $37.1 \%$ & $43.2 \%$ & $30.9 \%$ \\
\hline$\geq 13$ & $19.0 \%$ & $10.9 \%$ & $15.4 \%$ & $12.0 \%$ & $18.4 \%$ & $23.6 \%$ & $19.1 \%$ & $9.6 \%$ \\
\hline $\begin{array}{l}\text { Mean taxable } \\
\text { income, SEK }\end{array}$ & 6.62 & 5.77 & 6.01 & 6.62 & 6.02 & 5.94 & 6.00 & 6.21 \\
\hline Having children & $91.1 \%$ & $28.3 \%$ & $89.8 \%$ & $84.8 \%$ & $91.2 \%$ & $41.1 \%$ & $91.3 \%$ & $87.8 \%$ \\
\hline $\begin{array}{l}\text { Prior } \\
\text { cardiovascular } \\
\text { disease }\end{array}$ & $9.8 \%$ & $7.8 \%$ & $10.0 \%$ & $15.7 \%$ & $4.1 \%$ & $3.7 \%$ & $4.8 \%$ & $7.7 \%$ \\
\hline
\end{tabular}

found that unmarried people have an increased risk of incidence of dementia as compared with married individuals. The estimated protective effect of marriage persisted even after adjustment for several potential confounders. When only age was adjusted for, the benefit of marriage was stronger for men, particularly relative to being divorced, but after adjustment for socioeconomic and other factors, the initial gender difference was significantly reduced. In addition, marital status was related to early-onset and late-onset dementia, with a slightly higher risk for early-onset dementia, which has not been shown previously.
Our findings are consistent with previous study results showing a beneficial effect of marriage on dementia, ${ }^{3-7}$ suggesting that this association is highly robust. However, in contrast to these studies, which are based on smaller data sets, we find that the risk of dementia was observed across all non-married categories. Of note is that two recent studies, ${ }^{6}{ }^{7}$ including one by our research group, ${ }^{7}$ suggest a particular high risk among the widowed, but in this study with its large sample, we found a lower risk for widowhood compared with the other non-married categories. The lower estimate for the widowed might be related to the fact that dementia develops over a long period and that the

Table 2 Cox proportional hazard regression estimates of the association between marital status and dementia for young-old and middle-old group (fully adjusted model)

\begin{tabular}{|c|c|c|}
\hline & $\begin{array}{l}\text { Young-old } \\
\text { HR (95\% Cl) }\end{array}$ & $\begin{array}{l}\text { Middle-old } \\
\text { HR (95\% Cl) }\end{array}$ \\
\hline Age & $1.17(1.16 \text { to } 1.18)^{\star \star \star}$ & $1.18(1.17-1.19)^{\star \star \star}$ \\
\hline Men & Reference & Reference \\
\hline Women & $0.79(0.75 \text { to } 0.83)^{\star \star \star *}$ & $0.88(0.86 \text { to } 0.91)^{\star \star *}$ \\
\hline \multicolumn{3}{|c|}{ Having adult children } \\
\hline \multicolumn{3}{|c|}{ Education level, years } \\
\hline$\leq 9$ & Reference & Reference \\
\hline $10-12$ & 0.96 (0.91 to 1.02$)$ & $0.96(0.93 \text { to } 0.98)^{\star \star}$ \\
\hline$\geq 13$ & $0.77(0.70 \text { to } 0.83)^{\star \star \star}$ & $0.84(0.81 \text { to } 0.88)^{\star \star \star *}$ \\
\hline Taxable income & $0.89(0.88 \text { to } 0.90)^{\star \star * *}$ & $0.97(0.94 \text { to } 0.99)^{\star \star}$ \\
\hline Married & Reference & Reference \\
\hline Single & $1.71(1.57 \text { to } 1.87)^{\star \star \star}$ & $1.23(1.17 \text { to } 1.29)^{\star \star \star}$ \\
\hline Divorced & $1.79(1.68 \text { to } 1.90)^{\star \star \star}$ & $1.42(1.36 \text { to } 1.47)^{\star \star \star}$ \\
\hline Widowed & $1.28(1.14 \text { to } 1.43)^{\star \star \star}$ & $1.12(1.08 \text { to } 1.19)^{\star \star \star}$ \\
\hline
\end{tabular}


Table 3 Cox proportional hazard regression estimates of the association between marital status and dementia for young-old and middle-old group by gender

\begin{tabular}{|c|c|c|c|c|}
\hline & \multicolumn{2}{|l|}{ Model 1† } & \multicolumn{2}{|l|}{ Model 2‡ } \\
\hline & $\begin{array}{l}\text { Men } \\
\text { HR (95\% Cl) }\end{array}$ & $\begin{array}{l}\text { Women } \\
\text { HR }(95 \% \mathrm{Cl})\end{array}$ & $\begin{array}{l}\text { Men } \\
\text { HR }(95 \% \mathrm{Cl})\end{array}$ & $\begin{array}{l}\text { Women } \\
\text { HR }(95 \% \mathrm{Cl})\end{array}$ \\
\hline \multicolumn{5}{|l|}{ Young-old } \\
\hline Married & Reference & Reference & Reference & Reference \\
\hline Single & $2.12(1.94 \text { to } 2.32)^{\star \star \star}$ & $1.96(1.73 \text { to } 2.21)^{\star \star \star}$ & $1.72(1.54 \text { to } 1.94)^{\star * *}$ & $1.76(1.54 \text { to } 2.02)^{\star \star *}$ \\
\hline Divorced & $2.10(1.93 \text { to } 2.28)^{\star \star \star}$ & $1.70(1.55 \text { to } 1.86)^{\star \star \star}$ & $1.89(1.74 \text { to } 2.06)^{\star \star \star}$ & $1.68(1.53 \text { to } 1.85)^{\star \star \star}$ \\
\hline Widowed & $1.43(1.15 \text { to } 1.77)^{\star \star \star}$ & $1.31(1.15 \text { to } 1.50)^{\star \star \star}$ & $1.33(1.07 \text { to } 1.66)^{\star \star}$ & $1.24(1.09 \text { to } 1.42)^{\star \star \star}$ \\
\hline \multicolumn{5}{|l|}{ Middle-old } \\
\hline Married & Reference & Reference & Reference & Reference \\
\hline Single & $1.32(1.25 \text { to } 1.40)^{\star \star \star}$ & $1.18(1.10 \text { to } 1.27)^{\star \star \star}$ & $1.29(1.20 \text { to } 1.38)^{\star \star \star}$ & $1.16(1.07 \text { to } 1.25)^{\star \star \star}$ \\
\hline Divorced & $1.48(1.40 \text { to } 1.56)^{\star \star \star}$ & $1.36(1.29 \text { to } 1.43)^{\star \star *}$ & $1.47(1.39 \text { to } 1.55)^{\star * *}$ & $1.36(1.29 \text { to } 1.43)^{\star \star *}$ \\
\hline Widowed & $1.10(1.03 \text { to } 1.18)^{\star \star}$ & $1.11(1.06 \text { to } 1.15)^{\star \star \star}$ & $1.10(1.02 \text { to } 1.17)^{\star *}$ & $1.10(1.05 \text { to } 1.41)^{\star \star *}$ \\
\hline
\end{tabular}

duration of widowhood in this study might be of insufficient length for many people to be fully manifested in dementia during that time. This is in comparison to, for example, those living as single, which is a state that a person might have been in for a long time and perhaps even for his or her entire adult life. Hence, although we found a significantly increased risk of dementia for those widowed compared with their married counterparts, the risk ratios may have been somewhat underestimated.

Our study also adds evidence that all non-married statuses are associated with dementia for men and women. Since this study, to the best of our knowledge, is the first to explicitly examine this phenomenon, no direct comparison can be made between our estimates and those from previous studies. However, previous work on the risks of cognitive impairment has shown non-cohabiting men to be at greater risk compared with non-cohabiting women. ${ }^{6}$ Similar to those results, we found a relatively higher risk of cognitive impairment for divorced men, but after adjusting for socioeconomic and other factors, the HRs were still slightly higher among men than women, but now with overlapping CIs and no longer a statistically significant difference in risk. Thus, socioeconomic and other factors seem to account for some of the initially observed differences by gender in the association between marital status and dementia.

\section{Potential mechanisms}

While the specific mechanisms by which marital status influences the risk of dementia remain to be understood, several possible options, not necessarily mutually exclusive, have been hypothesised. First, a close relationship may be one of the best sources of cognitive stimulation, and may thereby be linked to the hypothesis of cognitive reserve. A higher cognitive reserve is suggested to provide the individual with resilience against neuropathological damage to the brain, such as occurs in dementia. ${ }^{17}$ In addition, a person who lives with someone may be less lonely and receive more social support, which is found to reduce psychological distress, including anxiety and depression. ${ }^{18}$ Individuals with more social support also have access to better resources for coping with stressors and are less prone to assess stressors as threatening. ${ }^{19}$ Moreover, being widowed or divorced is regarded as a severely stressful event, whereas marriage may serve as a buffer against the negative consequences of adverse life events. ${ }^{20}$ Although we were not able to adjust for these variables in this study, Sundström $e t a l^{7}$ adjusted for depressive symptoms and stressful life events but still observed a beneficial effect of marriage on the incidence of dementia.

Other proposed mechanisms concern the selection effect of marriage (which states that healthier people are more likely to both get and stay married) and the protection effect of marriage (which states that marriage provides increased social support and income, while also reducing unhealthy behaviours).$^{21}$ In our study, which consisted of upper middle-aged and elderly adults, we could not examine selection effects of marriage since most people marry long before the ages of the individuals we studied, but we could adjust for socioeconomic and health aspects (eg, education, income and cardiovascular diseases) at baseline. However, adjusting for these confounders did not notably influence the observed beneficial effect of marriage. Socioeconomic status at baseline may partially reflect the effects of marital status, but aspects such as low income may also reflect early onset of cognitive impairment. Although the tests of gender differences in estimated risks by marital status are somewhat sensitive to model specification, the overall conclusion of higher relative risks for unmarried individuals seemed not to be dependent on whether or not socioeconomic indicators were adjusted for.

\section{Limitations}

Our study has several possible limitations that need to be addressed. One is the use of a dementia diagnosis as 
provided by the national registers. Although previous studies using the Swedish National Patient and the Cause of Death Registers have reported very high specificity of dementia identification but lower sensitivity, ${ }^{15} 16$ there seems to be no difference in disease detection based on gender or education. ${ }^{15}$ In addition, there are many types of dementia, with Alzheimer's disease and vascular dementia as the two major forms, but there is also a considerable overlap between different subtypes of dementia, and distinguishing among them can be difficult, especially at an early stage and for early-onset dementia.

Furthermore, systematic differences by marital status in under-reporting and misclassification (sensitivity and specificity) may potentially be a source of biased estimates. In the absence of firm evidence, one can only speculate on this point. If anything, one would expect married people to be subject to examination at an earlier stage of dementia, for example, at the initiative of their partners, than those who are unmarried. ${ }^{22}$ Our estimates of higher risks among the non-married would then be biased downwards and represent an underestimation of differences in risk between married and unmarried individuals.

Another limiting aspect of the empirical framework is that events occurring after baseline are not adjusted for because of the potential risk of reversed causality. ${ }^{23}$ For this reason, differentiation depending on transition in or out of marital status during follow-up, such as remarriage, was not performed. Remarriage and divorce may in fact be outcomes that are partially determined by health status. However, robustness checks considering marital transition did not affect our main results.

\section{Conclusions and future work}

In conclusion, unmarried individuals, regardless of the marital status subcategory, appear to be at increased risk of early-onset and late-onset dementia. Although the results initially suggested a gender difference in the risk of dementia, the association between marital status and incidence of dementia does not seem to differ significantly between men and women in the fully adjusted model. Further studies are required to develop a better understanding of the mechanisms and pathways through which marriage plays a protective role regarding dementia in different age cohorts. Until then, the results of this study suggest opportunities for social-based interventions that target people living alone that may delay or even reduce the risk of dementia.

\section{Author affiliations}

${ }^{1}$ Department of Psychology, Umeå University, Umeå, Sweden

${ }^{2}$ Centre for Demographic and Ageing Research, Umeå University, Umeå, Sweden

${ }^{3}$ Umeå School of Business and Economics, Umeå University, Umeå, Sweden

Contributors AS participated in the design of the study and in data interpretation and statistical analyses. She also drafted the first version of the manuscript. OW participated in the design of the study, interpretation of the results, and in the drafting of the manuscript. EK managed the data set and performed some of the statistical analyses. All the authors read and approved the final manuscript.

Funding This research is funded by the Swedish Research Council (2006-21576-36119-66). AS also received funding from Riksbankens Jubileumsfond (P11-0876:1).

Disclaimer The sponsors had no role in the study design, data analyses, interpretation of data, writing of the report, or the decision to submit the article for publication.

\section{Competing interests None declared.}

Ethics approval The Linnaeus database has been approved by the Regional Ethical Committee at Umeå University DNR 07-1420.

Provenance and peer review Not commissioned; externally peer reviewed.

Data sharing statement No additional data are available.

Open Access This is an Open Access article distributed in accordance with the Creative Commons Attribution Non Commercial (CC BY-NC 4.0) license, which permits others to distribute, remix, adapt, build upon this work noncommercially, and license their derivative works on different terms, provided the original work is properly cited and the use is non-commercial. See: http:// creativecommons.org/licenses/by-nc/4.0/

\section{REFERENCES}

1. Alzheimer's Disease International. World Alzheimer Report. Ref Type: Online Source. 2009.

2. Crooks VC, Lubben J, Petitti DB, et al. Social network, cognitive function, and dementia incidence among elderly women. $A m \mathrm{~J}$ Public Health 2008;98:1221-7.

3. Fratiglioni L, Wang $\mathrm{HX}$, Ericsson $\mathrm{K}$, et al. Influence of social network on occurrence of dementia: a community-based longitudinal study. Lancet 2000;355:1315-19.

4. Bickel $\mathrm{H}$, Cooper $\mathrm{B}$. Incidence and relative risk of dementia in an urban elderly population: findings of a prospective field study. Psychol Med 1994;24:179-92.

5. Helmer C, Damon D, Letenneur L, et al. Marital status and risk of Alzheimer's disease: a French population-based cohort study. Neurology 1999;53:1953-8.

6. Håkansson K, Rovio S, Helkala EL, et al. Association between mid-life marital status and cognitive function in later life: population based cohort study. BMJ 2009;339:b2462.

7. Sundström A, Westerlund O, Mousavi-Nasab SM, et al. The relationship between marital and parental status and the risk of dementia. Int Psychogeriatr 2014;26:749-57.

8. Amieva $\mathrm{H}$, Stoykova $\mathrm{R}$, Matharan $\mathrm{F}$, et al. What aspects of social network are protective for dementia? Not the quantity but the quality of social interactions is protective up to 15 years later. Psychosom Med 2010;72:905-11.

9. House JS, Landis KR, Umberson D. Social relationships and health. Science 1988;241:540-5.

10. Williams K, Umberson D. Marital status, marital transitions, and health: a gendered life course perspective. J Health Soc Behav 2004:45:81-98.

11. Ross CE, Mirowsky J, Goldsteen K. The impact of the family on health: the decade in review. J Marriage Fam 1990;52:1059-78.

12. Malmberg G, Nilsson LG, Weinehall L. Longitudinal data for interdisciplinary ageing research. Design of the Linnaeus Database. Scand J Publ Health 2010;38:761-7.

13. Ludvigsson J, Andersson E, Ekbom A, et al. External review and validation of the Swedish National Inpatient Register. BMC Public Health 2011;11:450.

14. National Board of Health and Welfare, Causes of death 2002 [In Swedish]. http://www.socialstyrelsen.se/Lists/Artikelkatalog/ Attachments/11233/2002-42-4_2002424.pdf

15. Feldman A, Rizzuto D, Narasimhalu K, et al. Validity of dementia diagnoses in two Swedish health registers. Alzheimers Dement 2012;8:493.

16. Jin YP, Gatz M, Johansson B, et al. Sensitivity and specificity of dementia coding in two Swedish disease registries. Neurology 2004;63:739-41.

17. Scarmeas N, Stern $\mathrm{Y}$. Cognitive reserve and lifestyle. J Clin Exp Neuropsychol 2003;25:625-33. 
18. Hansson $\mathrm{RO}$, Jones $\mathrm{WH}$, Carpenter $\mathrm{BN}$, et al. Loneliness and adjustment to old age. Int J Hum Dev 1986-1987;27:41-53.

19. Cohen S, Wills TA. Stress, social support, and the buffering hypothesis. Psychol Bull 1985;98:310-57.

20. Trivedi JK, Sareen H, Dhyani M. Psychological aspects of widowhood and divorce. Mens Sana Monogr 2009;7:37-49.
21. Waldron I, Hughes ME, Brooks TL. Marriage protection and marriage selection-prospective evidence for reciprocal effects of marital status and health. Soc Sci Med 1996;43:113-23.

22. Savva GM, Arthur A. Case-finding for dementia: who are the undiagnosed? Age Ageing 2014;43(Suppl 2):ii21. Abstract.

23. Fisher LD, Lin DY. Time-dependent covariates in the Cox proportional-hazards regression model. Annu Rev Public Health 1999;20:145-57. 